\title{
Pleiotropic Effects of Antithrombin Strand 1C Substitution Mutations
}

David A. Lane, Robin J. Olds, Jacqueline Conard, Michael Boisclair, Susan Clark Bock, Mae Hultin, Ulrich Abildgaard, Helen Ireland, Elizabeth Thompson, Geza Sas, Marie Helene Horellou, Giacomo Tamponi, and Swee-Lay Thein Charing Cross and Westminster Medical School, London W6 8RP; Institute of Molecular Medicine, John Radcliffe Hospital, Oxford OX3 9DU, United Kingdom; Hôpital Hôtel Dieu (Professor Samama), 75181 Paris, France; The Thrombosis Center, Temple University Medical School, Philadelphia, Pennsylvania 19140; State University of New York at Stony Brook, New York 11790; Aker University Hospital, N-0514 Oslo, Norway; Post Graduate Medical University, H-1502 Budapest, Hungary; and Cattedra Di Ematologia, 10126 Torino, Italy

\begin{abstract}
Six different substitution mutations were identified in four different amino acid residues of antithrombin strand $1 \mathrm{C}$ and the polypeptide leading into strand 4B (F402S, F402C, F402L, $\mathrm{A404T}$, N405K, and P407T), and are responsible for functional antithrombin deficiency in seven independently ascertained kindreds (Rosny, Torino, Maisons-Laffitte, Paris 3, La Rochelle, Budapest 5, and Oslo) affected by venous thromboembolic disease. In all seven families, variant antithrombins with heparin-binding abnormalities were detected by crossed immunoelectrophoresis, and in six of the kindreds there was a reduced antigen concentration of plasma antithrombin. Two of the variant antithrombins, Rosny and Torino, were purified by heparin-Sepharose and immunoaffinity chromatography, and shown to have greatly reduced heparin cofactor and progressive inhibitor activities in vitro. The defective interactions of these mutants with thrombin may result from proximity of s1C to the reactive site, while reduced circulating levels may be related to s1C proximity to highly conserved internal $\beta$ strands, which contain elements proposed to influence serpin turnover and intracellular degradation. In contrast, $\mathbf{s 1 C}$ is spatially distant to the positively charged surface which forms the heparin binding site of antithrombin; altered heparin binding properties of s1C variants may therefore reflect conformational linkage between the reactive site and heparin binding regions of the molecule. This work demonstrates that point mutations in and immediately adjacent to strand $1 \mathrm{C}$ have multiple, or pleiotropic, effects on this serpin, leading ultimately to failure of its regulatory function. (J. Clin. Invest. 1992. 90:2422-2433.) Key words: serpin • variant $\bullet$ heparin $\bullet$ thrombin $\bullet$ deficiency $\bullet$ antithrombin III
\end{abstract}

\section{Introduction}

Antithrombin is a member of the serine proteinase inhibitor (serpin) superfamily (1). Its main function is the regulation of blood coagulation proteinases, such as thrombin, that are generated during coagulation activation (2-4). Antithrombin has two distinct functional domains: one (the reactive site) interacts with the proteinase, and the other binds to heparin. Mainte-

Address correspondence to David A. Lane, Ph.D., Department of Haematology, Charing Cross and Westminster Medical School, Hammersmith, London W6 8RP, United Kingdom.

Received for publication 18 February 1992 and in revised form 24 July 1992.

J. Clin. Invest.

(c) The American Society for Clinical Investigation, Inc.

$0021-9738 / 92 / 12 / 2422 / 12 \quad \$ 2.00$

Volume 90, December 1992, 2422-2433 nance of an adequate level, $>70 \%$, of functional antithrombin activity in blood is essential to ensure effective inhibition of coagulation proteinases: inheritance of genetic defects that lower the absolute amount of antithrombin (type I), or that produce inactive ( variant) forms of the inhibitor (type II), predispose to familial thrombotic disorders $(5,6)$.

Numerous variants of antithrombin have now been characterized at the molecular level (7). Mutations that alter the reactive site (types IIa and IIb) are generally located near the $\mathrm{COOH}$ terminus of the molecule, while heparin binding defects (type IIc) (classification according to Sas et al. [8, 9]) are usually caused by single amino acid substitutions near the $\mathrm{NH}_{2}$ terminus.

We have studied seven different families in which the propositi suffered thromboembolic disorders and were found to have reduced levels of functional antithrombin. We show here that variant proteins are produced in each case and we identify the genetic abnormalities responsible for the altered functional properties of the antithrombins. Amongst these seven families, there are six different point mutations leading to single amino acid substitutions in the 402-407 region of the antithrombin protein. These substitutions have pleiotropic (multiple) effects; they alter the reactive site and heparin-binding properties of the variant antithrombins, and decrease their circulating levels in most cases.

\section{Methods}

\section{Family histories}

The descriptions of the family histories that follow should be considered together with the antithrombin assay results summarized in Table I.

\section{Case 1}

An 18-yr-old male from the town of Rosny, France, was referred for investigation in August 1989, because of a history of deep vein thrombosis (DVT). ${ }^{1}$ At the age of $15 \mathrm{yr}$, he developed a spontaneous superficial vein thrombosis of the right leg. 2 yr later, he had a DVT (diagnosed by venography), $7 \mathrm{~d}$ after appendectomy. He was treated with heparin, followed by oral anticoagulants for a period of $7 \mathrm{mo}$. Repeated echo-Doppler studies showed persistence of obstruction of the left superficial femoral and iliac veins. Antithrombin deficiency was diagnosed on the basis of reduced levels of activity and antigen in plasma, with the former being consistently lower than the latter (activity $52 \%$, antigen $70 \%$ ).

His mother, aged $37 \mathrm{yr}$, originating from Gabon, also has antithrombin deficiency (activity 46\%, antigen 60\%). She had a clinically diagnosed left calf vein thrombosis at the age of $26 \mathrm{yr}$, while receiving estroprogestogen. It should be noted that she has had three pregnancies

1. Abbreviations used in this paper: $\mathrm{CIE}$, crossed immunoelectrophoresis; DVT, deep vein thrombosis; PCR, polymerase chain reaction. 
without prophylactic anticoagulant treatment (one before and two after the thrombosis) and that she also received estroprogestogen after her second pregnancy: no other episodes of thrombosis were observed. The propositus has no contact with his father who could not therefore be examined.

\section{Case 2}

A 16-yr-old male from Torino, Italy, was referred for investigation after a DVT of the right leg. Possible predisposing events were repeated trauma of the same leg 1 wk and 1 mo before. The thrombosis was confirmed by echo-Doppler and computerized tomography: popliteal, superficial femoral, and iliac veins were occluded. He was treated first with urokinase together with heparin. Levels of antithrombin were determined to be low (activity $46 \%$, antigen $69 \%$ ) and were taken to indicate increased consumption; consequently, he received antithrombin concentrates $(1,000 \mathrm{U}$ on day $2 ; 2,000 \mathrm{U}$ on day $3 ; 3,000 \mathrm{U}$ from day 5-10). Warfarin was started on day 10 and heparin stopped on day 13. Oral anticoagulants were continued for 6 mo. Echo-Doppler performed at 4 mo showed a thrombosis up to the iliac vein and a collateral circulation by the internal saphenous vein. Antithrombin levels in his parents and his sister were normal and there was no family history of thrombosis.

\section{Case 3}

This involves an affected man (activity $56 \%$, antigen $73 \%$ ) from Maisons-Laffitte, France, with only one episode of left calf vein thrombosis at the age of $55 \mathrm{yr}$. He was referred for familial thromboembolic antecedents: his sister, aged $40 \mathrm{yr}$, developed a left ilio-femoral venous thrombosis with pulmonary embolism at the age of $28 \mathrm{yr}$, after a knee ligamentoplasty performed without interruption of estroprogestative pill. She was treated with oral anticoagulants for $2 \mathrm{yr}$ without a further episode of thrombosis. At the age of $30 \mathrm{yr}$, she received prophylactic anticoagulant treatment for $2 \mathrm{yr}$ after knee surgery. Despite her thrombosis, her antithrombin levels in plasma appear to be normal (activity $105 \%$, antigen $104 \%$ ).

An affected (antithrombin activity 55\%, antigen $75 \%$ ) son of the propositus, 32 yr old, developed a spontaneous left ilio-femoral thrombosis at the age of $17 \mathrm{yr}$. He was treated with heparin followed by oral anticoagulants for $2 \mathrm{yr}$. $10 \mathrm{yr}$ later he developed a spontaneous ilio-femoral thrombosis and for the last $3 \mathrm{yr}$ has been treated with acenocoumarol, without recurrence of thrombotic episodes.

Two other sons, 26 and 18 yr old, have no history of thrombosis and their antithrombin levels are normal. A 25-yr-old unaffected (i.e., with normal antithrombin levels) nephew (son of an unaffected brother), however, presented with a left calf vein thrombosis after appendectomy at the age of $17 \mathrm{yr}$. After $1 \mathrm{yr}$ of treatment on acenocoumarol, this was discontinued and he has been free of recurrences for $3 \mathrm{yr}$.

The occurrence of thrombosis in this third family, often present in association with normal antithrombin levels, suggests a second independent abnomality, the nature of which is presently unknown.

\section{Case 4}

The propositus of the antithrombin Paris 3 kindred is a 41 -yr-old male (antithrombin activity $48 \%$, antigen $72 \%$ ). At the age of $20 \mathrm{yr}$ he had a fracture of the right malleolus which required a plaster cast for $40 \mathrm{ds}$ : calf oedema followed cast removal. At the age of $35 \mathrm{yr}$, surgery was planned for inguinal hernia and, as his mother and two sisters were also known to be antithrombin deficient (Table I), he was examined for thrombosis by echo-Doppler: signs of previous right femoro-popliteal thrombosis were found. At the age of $39 \mathrm{yr}$, he experienced superficial thrombosis which was treated with a low molecular weight heparin. After another thrombotic episode, echo-Doppler demonstrated sequelae of right and left side DVT. Consequently, he has been put on long-term oral anticoagulants.

One affected sister (antithrombin activity $60 \%$, antigen $78 \%$ ), aged $44 \mathrm{yr}$, has had repeated DVT and pulmonary embolism after deliveries and an induced abortion. A second affected sister (activity 54\%, antigen $70 \%$ ), aged $51 \mathrm{yr}$ has had no thrombosis, despite having three children. One of these children is antithrombin deficient (activity $58 \%$, antigen $65 \%$ ) and has had a DVT. Furthermore, the mother of the propositus, $71 \mathrm{yr}$, had postpartum superficial thrombosis at $17 \mathrm{yr}$, followed by a second thrombosis during the next pregnancy. At 62 yr she experienced ilio-femoral thrombosis, which was treated with long-term oral anticoagulants.

\section{Case 5}

The propositus (antithrombin activity 55\%, antigen $73 \%$ ) of the antithrombin La Rochelle kindred had repeated sprains between the ages of 17 and $28 \mathrm{yr}$, the last one being associated with pain and oedema. Diagnosis of DVT was suggested for the first time when he was $28 \mathrm{yr}$, after leg pain. Repeated episodes of dyspnoea culminated in investigation by venography, which revealed a previous left and recent right thrombosis. He received heparin, and during treatment a pulmonary embolism was confirmed by lung scan. Urokinase/plasminogen treatment was given and a vena caval interruption was performed. For the last $14 \mathrm{yr}$, he has been given oral anticoagulants.

His mother, who also has reduced antithrombin levels (activity $55 \%$, antigen 54\%), is now $67 \mathrm{yr}$ old and experienced no thrombotic problems following an appendectomy at $18 \mathrm{yr}$ and her first three pregnancies. She experienced a left DVT after the fourth delivery and has had repeated episodes of superficial thrombophlebitis. She is not treated with long-term oral anticoagulants.

His sister (antithrombin activity 56\%, antigen 60\%), aged $44 \mathrm{yr}$, developed a left calf DVT at 22 yr: thrombosis was associated with prolonged bed rest after influenza. She was treated with heparin for 48 $\mathrm{h}$ and oral anticoagulants were begun, but the DVT extended up the thigh and into the pelvis. Heparin was given again and after a move to oral anticoagulants she developed a DVT of the right leg. Additional episodes of DVT were investigated by venography, which revealed extensive thrombosis of the right femoral, external, and common iliac veins. Recurrency of thrombosis after stopping anticoagulants has lead to oral anticoagulation for the past $20 \mathrm{yr}$.

\section{Case 6}

This involves a family from Budapest, Hungary, with an extensive pedigree and a history of severe thrombotic episodes. A combination of at least two defects (antithrombin and protein $\mathrm{C}$ deficiencies), which apparently segregate separately, can explain the severe thrombosis. A comprehensive report of the family history has appeared elsewhere (10). While only the propositus was investigated in the present study (antithrombin activity $70 \%$, antigen $100 \%$ ), it is instructive to review briefly the family history. Of 10 brothers and 2 sisters, at least 2 siblings died of pulmonary embolism at an early age ( 21 and $16 \mathrm{yr}$ ). Two other children died without definite (autopsy) diagnosis. Four other family members with functional antithrombin deficiency suffered from severe thromboembolism at 15,19,23, and $46 \mathrm{yr}$ and survived. Three family members (the grandmother and two brothers) with functional antithrombin deficiency have not developed thrombosis. Available antithrombin levels, including those reported elsewhere (10), are listed in Table I.

\section{Case 7}

Case 7 involves an antithrombin deficient kindred from Oslo, Norway. Details of the family history are contained in a report (11) that was the first to recognize an association between inherited antithrombin deficiency and venous thrombosis. More recently, Hultin et al. (12) analyzed plasma from members of this family by crossed immunoelectrophoresis (CIE) in the presence of heparin and observed a cathodal variant protein in affected individuals. While the inheritance of antithrombin deficiency and its association with thrombosis is well documented in this family, a brief updated summary is required. The propositus (antithrombin activity $50 \%$, antigen $48 \%$ ) has had several, severe thromboses involving obstruction of the mesenteric veins, necessitating removal of much of his small bowel. Of 25 family members investigated, 12 were found to have functional antithrombin deficiency (see Table I). Eight of these individuals have had DVT, and in seven 
this was recurrent. The mean age of onset of the first DVT was $19 \mathrm{yr}$ of age.

\section{Protein investigations}

Assays of antithrombin levels in plasma were performed by antigen and functional methods. Antigen levels of cases 1-6 were measured using Nor Partigen plates (Behringwerke, Marburg, FRG) or a nephelometric method (Nephelometric Analyzer, Behringwerke), while the functional assay employed a heparin cofactor method using either $S$ 2222 (KabiVitrum, Uxbridge, UK), or Dupont reagents and an ACA SX Instrument. Functional and immunological antithrombin levels for case 7 were determined as previously described $(11,13,14)$.

CIE was performed with heparin in the first dimension $(9,15)$, as described $(12,16)$. The polyclonal antibodies were purchased from DakoPatts (High Wycombe, UK) and Behringwerke.

Normal pooled plasma was prepared by centrifugation of citrated blood from healthy laboratory staff. Citrated plasma was also prepared from the propositi, all of whom are shown to be heterozygous for variant antithrombins (hereafter termed antithrombins Rosny, Torino, Maisons-Laffitte, Paris 3, La Rochelle, Budapest 5, and Oslo). An- tithrombin was isolated from normal plasma and from the propositi with antithrombins Rosny and Torino (insufficient plasma was available from the other families) by chromatography on heparin-Sepharose (Pharmacia Fine Chemicals, Uppsala, Sweden) $(16,17)$. Plasma $(\sim 30 \mathrm{ml})$ was applied to the column in $0.1 \mathrm{M}$ Tris- $\mathrm{HCl}, \mathrm{pH} 7.4$, containing $0.4 \mathrm{M} \mathrm{NaCl}$ : plasma with antithrombin Rosny was subject to a preliminary precipitation step with dextran sulphate. Under the conditions used, approximately half of the antithrombin in each case did not bind to the column and was recovered in the breakthrough fraction containing most of the plasma; when the same quantity of normal plasma was applied to the same column, minimal amounts (barely detectable) of antithrombin did not bind. The breakthrough fractions from the patients' plasmas were separately pooled. The abilities of the two pools to form thrombin-antithrombin complex were studied using an immunoassay ( see below). The variant antithrombins were then isolated from these pooled fractions by immuno-affinity chromatography on immobilized polyclonal antibody (DakoPatts) to normal antithrombin (18). The samples were applied to the column in $0.05 \mathrm{M}$ Tris- $\mathrm{HCl}$, $\mathrm{pH} 7.4$, containing $0.5 \mathrm{M} \mathrm{NaCl}$ and $0.5 \%$ (vol/vol) Tween 80. Elution was achieved with $4.5 \mathrm{M} \mathrm{MgCl}_{2}$ in $0.25 \mathrm{M}$ Tris $\mathrm{HCl}$,

Table I. Antithrombin Assays on Plasma

\begin{tabular}{|c|c|c|c|c|c|}
\hline & Activity & Antigen & & Activity & Antigen \\
\hline Normal plasma & $\begin{array}{c}100 \\
(80-120)\end{array}$ & $\begin{array}{c}100 \\
(80-120)\end{array}$ & $\begin{array}{l}\text { Case 5: antithrombin La Rochelle, } \\
\text { AAC to AAG, N405K }\end{array}$ & & \\
\hline & & & Propositus & 55 & $73 \mathrm{~T}$ \\
\hline Case 1: antithrombin Rosny, TTC to & & & Mother & 55 & $54 \mathrm{~T}$ \\
\hline $\begin{array}{l}\text { TGC, F402C } \\
\text { Propositus }\end{array}$ & 52 & $70 \mathrm{~T}$ & Sister & 56 & $60 \mathrm{~T}$ \\
\hline Cop 2 ontithmombin Torim TTC to & 46 & $60 \mathrm{~T}$ & $\begin{array}{l}\text { Case 6: antithrombin Budapest 5,* } \\
\text { CCT to ACT, P407T }\end{array}$ & & \\
\hline Case 2: antithrombin Torino, TTC to & & & Propositus & 70 & $100 \mathrm{~T}$ \\
\hline TCC, F402S & & & Daughter & 75 & $104 \mathrm{~T}$ \\
\hline Propositus & 46 & $69 \mathrm{~T}$ & Grandmother & 70 & 95 \\
\hline Mother & 102 & 109 & Brother & 65 & $90 \mathrm{~T}$ \\
\hline Father & 114 & 96 & Brother & 90 & $100 \mathrm{~T}$ \\
\hline Sister & 94 & 100 & Brother & 105 & 105 \\
\hline Case 3: antithrombin Maisons-Laffitte, & & & Brother & 60 & 100 \\
\hline TTC to TTA, F402L & & & Brother & 70 & 94 \\
\hline Propositus & 56 & $73 \mathrm{~T}$ & Brother & 90 & 90 \\
\hline Son & 55 & $75 \mathrm{~T}$ & Case 7: antithrombin Oslo ${ }^{\ddagger} \mathrm{GCC}$ to & & \\
\hline Son & 111 & 100 & ACC, A404T & & \\
\hline Son & 98 & 100 & Propositus & 50 & $48 \mathrm{~T}$ \\
\hline Brother & 98 & 98 & Daughter & 49 & 64 \\
\hline Newphew & 100 & $107 \mathrm{~T}$ & Daughter & 63 & ND T \\
\hline Sister & 105 & $104 \mathrm{~T}$ & Nephew & 66 & ND \\
\hline Case 4: antithrombin Paris 3, GCC to & & & Nephew & 54 & ND T \\
\hline $\mathrm{ACC}, \mathrm{A} 404 \mathrm{~T}$ & & & Daughter & 60 & ND T \\
\hline Propositus & 48 & $72 \mathrm{~T}$ & Niece & 49 & ND \\
\hline Mother & nd & $70 \mathrm{~T}$ & Niece & 50 & ND T \\
\hline Sister & 60 & $78 \mathrm{~T}$ & Grandson & 50 & ND \\
\hline Sister & 54 & 70 & Sister & 40 & ND T \\
\hline \multirow[t]{2}{*}{ Nephew } & 58 & $65 \mathrm{~T}$ & Brother & 47 & ND T \\
\hline & & & Brother & 53 & ND T \\
\hline
\end{tabular}

Results (\%) of functional (activity) and immunological (antigen) assays on plasma samples obtained from normal laboratory controls and individuals from the affected families studied in this investigation. Some of the results of assays on the antithrombin Budapest 5 and Oslo kindreds are taken from previous reports $(10-12)$.

$T$, thrombosis; ND, not done.

* Some of the results from this kindred were originally reported elsewhere, see Family histories in Methods.

${ }^{\ddagger}$ Because of the large kindred, only results of those individuals with antithrombin deficiency are given. 
pH 6.9 (19), after extensive washing with the application buffer. Normal antithrombin was also isolated from plasma using this column. For kinetic studies, the antithrombins (normal and variant) were subjected to an additional purification step on ion exchange chromatography, to remove any contaminating heparin from the heparin-Sepharose step (20).

The abilities of the variant antithrombins (Rosny and Torino) in pooled breakthrough fractions to form thrombin-antithrombin complex were compared to that of antithrombin in normal plasma using a commercial assay (Enzygnost-TAT; Behringwerke). Samples were diluted to give a final antithrombin concentration (determined by Nor Partigen plates) of $5.38 \mathrm{nM}$ and then incubated at $37^{\circ} \mathrm{C}$ with human $\alpha$ thrombin (a kind gift from Dr. Jean-Marie Freyssinet, Institute d'Hematologie et d'Immunologie, Strasbourg, France), $27.8 \mathrm{nM}$, in $50 \mathrm{mM}$ Tris- $\mathrm{HCl}, 150 \mathrm{mM} \mathrm{NaCl}, 0.02 \%$ (wt/vol) sodium azide, $\mathrm{pH}$ 7.8. Complex formation was compared in the absence and presence of 0.015 $\mathrm{IU} / \mathrm{ml}$ heparin (Leo Laboratories, Princes Risborough, UK). After the addition of thrombin, aliquots $(20 \mu \mathrm{l})$ were removed at timed intervals and immediately reacted with $5 \mu \mathrm{l}$ of $1,000 \mathrm{U} / \mathrm{ml}$ hirudin (kindly supplied by Dr. R. Wallace, Ciba Geigy, Horsham, UK). Before assay, the inhibited reaction mixtures were diluted fivefold in normal plasma.
SDS PAGE and immunoblotting were performed under nonreducing conditions using 10-15\% Phast Gels (Pharmacia) and rabbit antiantithrombin polyclonal antibody (DakoPatts), as described (21).

The reaction of purified antithrombin (normal antithrombin and antithrombins Rosny and Torino) with thrombin was studied at $37^{\circ} \mathrm{C}$ in the absence of heparin. Purified human thrombin ( $20 \mathrm{nM})$ was incubated with various concentrations of antithrombins (see Fig. 5) in $0.15 \mathrm{M} \mathrm{NaCl}, 0.05 \mathrm{M}$ Tris- $\mathrm{HCl}, \mathrm{pH} 7.4$, containing $0.1 \%$ polyethylene glycol $6,000(18,22)$. At different times, subsamples were withdrawn and added to cuvettes containing the chromogenic substrate S2238 (KabiVitrum) to determine residual thrombin activity. Relative velocity, $\mathrm{V} / \mathrm{V}_{\mathrm{o}}$, where $\mathrm{Vo}_{\mathrm{o}}$ is the initial velocity, of substrate hydrolysis was plotted against time.

\section{DNA amplification and direct sequencing}

Genomic DNA was isolated from peripheral blood leukocytes of each of the subjects investigated. For all cases, the polymerase chain reaction (PCR) was used to amplify specifically segments of the antithrombin gene that encode the seven exons and flanking intron sequences. Oligonucleotide primers and thermal cycling conditions have been described previously (23-25). One of a pair of amplification primers was 5'-bio-
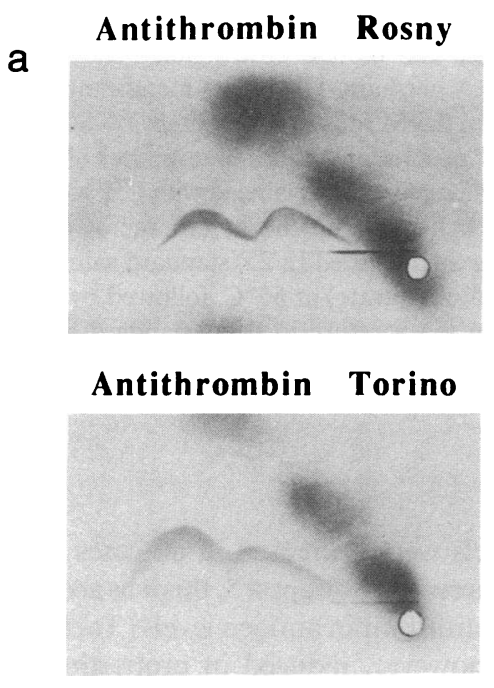

b

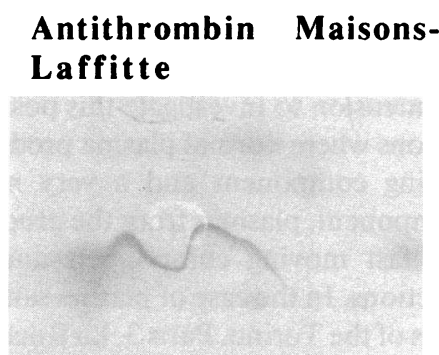

Normal antithrombin

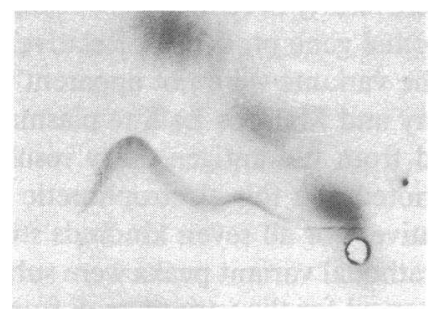

Antithrombin Oslo

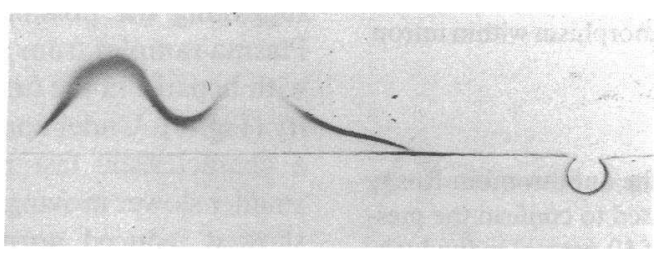

Antithrombin Utah

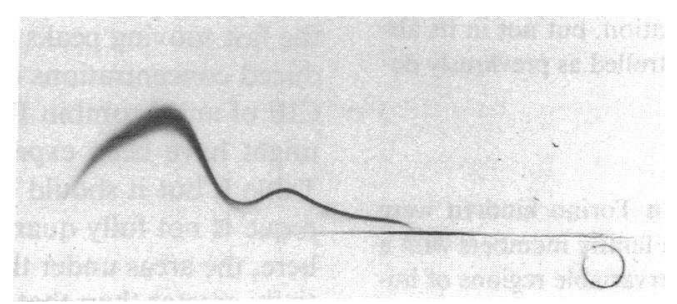

C Antithrombin Paris 3

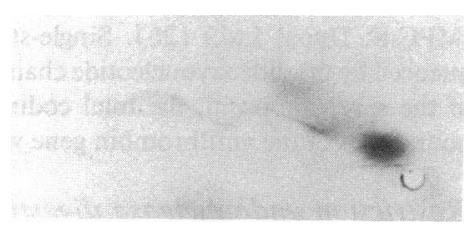

Antithrombin La Rochelle

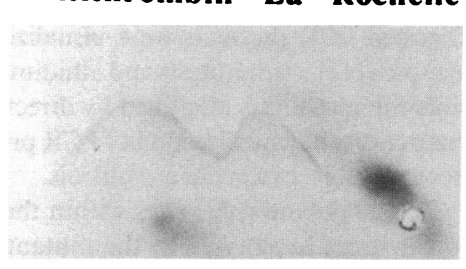

Antithrombin Budapest 5

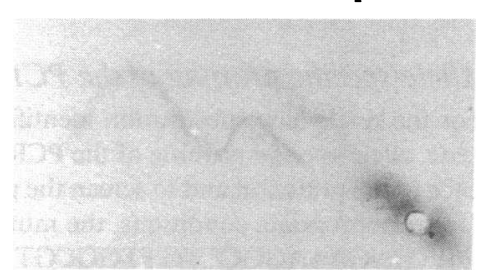

Normal antithrombin

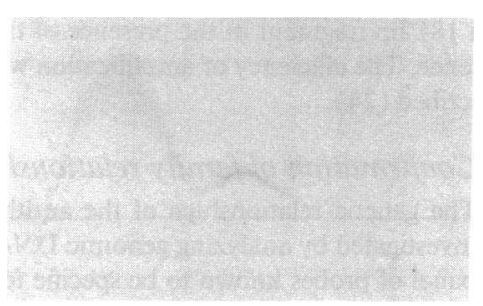

Figure 1. CIE in the presence of heparin. (a) Plasma samples from the propositi of the antithrombins Rosny, Torino, Maisons-Laffitte kindred and a normal control. (b) Samples from patients of the antithrombin Oslo and Utah kindred. (c) Plasma samples from propositi with antithrombins Paris 3, La Rochelle, Budapest 5, and a normal control. 


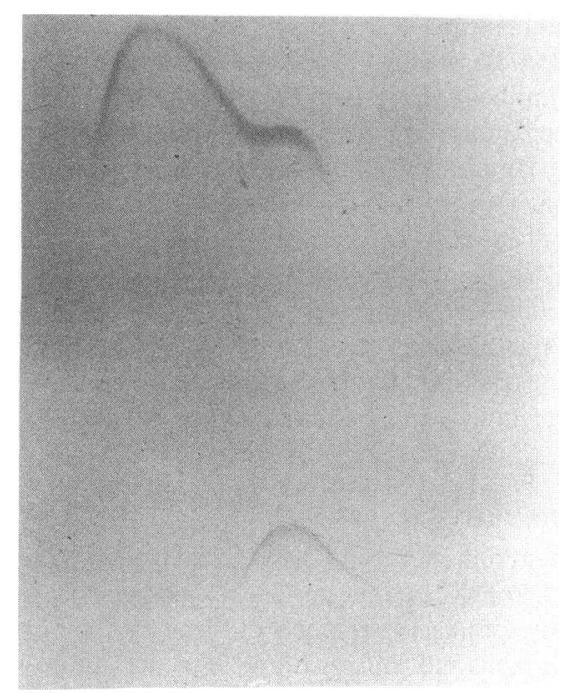

ANTITHROMBIN ROSNY

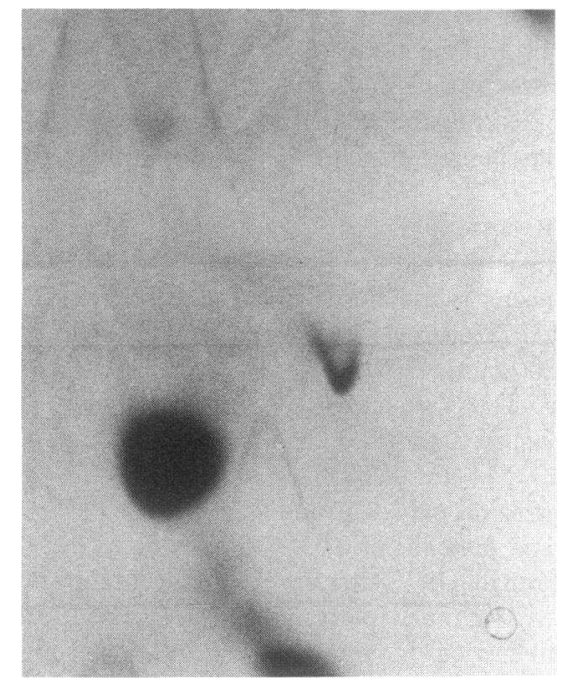

ANTITHROMBIN TORINO
Figure 2. Separation of antithrombins Rosny and Torino from plasma by heparin-Sepharose chromatography. Plasma from the propositi with these variants were applied to the column in $0.4 \mathrm{M} \mathrm{NaCl}$ and eluted with $2.0 \mathrm{M} \mathrm{NaCl}$ (see Methods). The top crossed immunoelectrophoretic patterns were obtained from the fraction of (mainly normal) antithrombin that bound to the column in $0.4 \mathrm{M} \mathrm{NaCl}$, while the bottom patterns were obtained from the (variant) fractions that did not bind. tinylated to allow preparation of single stranded template from the amplified DNA using magnetic beads (Dynabeads M-280 Streptavidin; Dynal Ltd., Wirral, UK) and a magnetic particle concentrator (MPC-E; Dynal Ltd.) (26). Single-stranded DNA was directly sequenced by the dideoxynucleotide chain termination method. For each of the seven propositi, the total coding region and the intron-exon boundaries of the antithrombin gene were sequenced.

\section{Restriction endonuclease digestion of the PCR products and haplotype analysis}

Restriction enzymes were purchased from Boehringer Mannheim (Lewes, UK) and used according to the manufacturer's instructions. Digested PCR products were visualized under ultraviolet light, after agarose gel electrophoresis and ethidium-bromide staining. Where possible the mutations identified by direct sequencing were confirmed by restriction enzyme digestion of PCR products, DNA from a panel of 50 normal subjects serving as controls.

Three polymorphic sites within the antithrombin locus were used to construct haplotypes of the mutant alleles for antithrombins Oslo and Paris 3; a 5'-end length polymorphism (27), a PstI site polymorphism within exon 4 (28), and a DdeI site polymorphism within intron $5(29)$.

\section{Allele-specific priming of the PCR}

For the single base substitution identified in the antithrombin Rosny gene, allele-specific priming of the PCR was used to confirm the presence of the mutation and to screen the panel of 50 normal individuals. Under appropriate conditions, the mutant allele-specific oligonucleotide (5'-GAAAGGCCTGTTGGCGTTGC , mutation site underlined), in combination with a normal sequence upstream primer (5'GCTGTGTCTGTGGATGATTTA), resulted in the amplification of a 181-bp fragment in the presence of the mutation, but not in its absence. The efficiency of amplification was controlled as previously described (24).

\section{Confirmation of family relationships}

The genetic relationships of the antithrombin Torino kindred were investigated by analyzing genomic DNA from family members with a panel of probes known to be specific for hypervariable regions of human DNA (30); these were kindly supplied by Professor Alec Jeffries, Leicester University, UK. Genomic DNA from the propositus, his sister, and both parents was completely digested with the restriction endonuclease Hinf I (Boehringer Mannheim, Lewes, UK). The DNA was electrophoresed in $0.8 \%$ agarose and blotted onto nylon membrane (Hybond N; Amersham Int'l., Amersham, UK). The membrane was prehybridized for $1 \mathrm{~h}$ at $65^{\circ} \mathrm{C}$ in $0.5 \mathrm{M}$ sodium phosphate, 7\% SDS, 1 mM EDTA, pH 7.2. A panel of human minisatellite probes (MS1, MS2, MS29, MS31, MS43, MS51, p $\lambda$ G3) was labeled with [ $\left.{ }^{32} \mathrm{P}\right] \mathrm{dCTP}$ by random priming and was hybridized to the membrane at $65^{\circ} \mathrm{C}$ overnight. The membrane was then washed in $2 \times$ standard saline citrate $(0.3 \mathrm{M} \mathrm{NaCl}, 30 \mathrm{mM}$ sodium citrate $)$ at $65^{\circ} \mathrm{C}$, followed by high stringency washes at the same temperature in $0.1 \times$ standard saline citrate, $0.1 \%$ SDS for 15 min each. Autoradiography was performed overnight at $-80^{\circ} \mathrm{C}$.

\section{Results}

Antithrombin activity levels were decreased in all cases and, with the exception of antithrombin Budapest 5, this was accompanied by a reduction in antithrombin antigen levels (Table I). Antigen levels were not, however, reduced in proportion to functional activity levels for six out of seven cases in this series, suggesting the possibility of dysfunctional variant proteins. Plasma samples from all seven families were subjected to CIE with heparin in the first dimension to investigate this possibility (Fig. 1). Under conditions where normal plasma produced a characteristic fast moving component and a very much smaller slower moving component, plasmas from the propositi showed reduced normal, fast moving components and increased slower moving fractions. In the case of plasma samples from affected heterozygotes of the Torino, Paris 3, La Rochelle, Budapest 5, and Oslo kindreds, the slow moving variant peaks (mutant gene products) were clearly of reduced size relative to the fast moving peaks (normal gene products). Relatively reduced concentrations of the variants were not apparent from CIE of antithrombin Rosny and Maisons-Laffitte plasmas, as might have been expected from the antigen assay results in Table I, but it should be noted that this electrophoretic technique is not fully quantitative. For all seven kindreds studied here, the areas under the cathodal variant peaks were substantially greater than that observed for the variant peak from antithrombin Utah, a previously identified substitution mapping to the same region of the antithrombin molecule (31).

Antithrombins Rosny and Torino were isolated using hepa- 
rin-Sepharose chromatography as a preliminary step. Plasma samples were applied in $0.4 \mathrm{M} \mathrm{NaCl}$ and the majority of their slow moving components did not bind to the column, Fig. 2 . The ability of these variant antithrombin fractions to inactivate thrombin was studied using a thrombin-antithrombin complex immunoassay. As can be seen in Fig. 3, the variant antithrombins from both patients did not form thrombin-antithrombin complexes, either in the absence or presence of heparin.

The variants were further purified from the heparin-Sepharose column breakthrough fractions by application to and elution from an anti-antithrombin-Sepharose column. They were
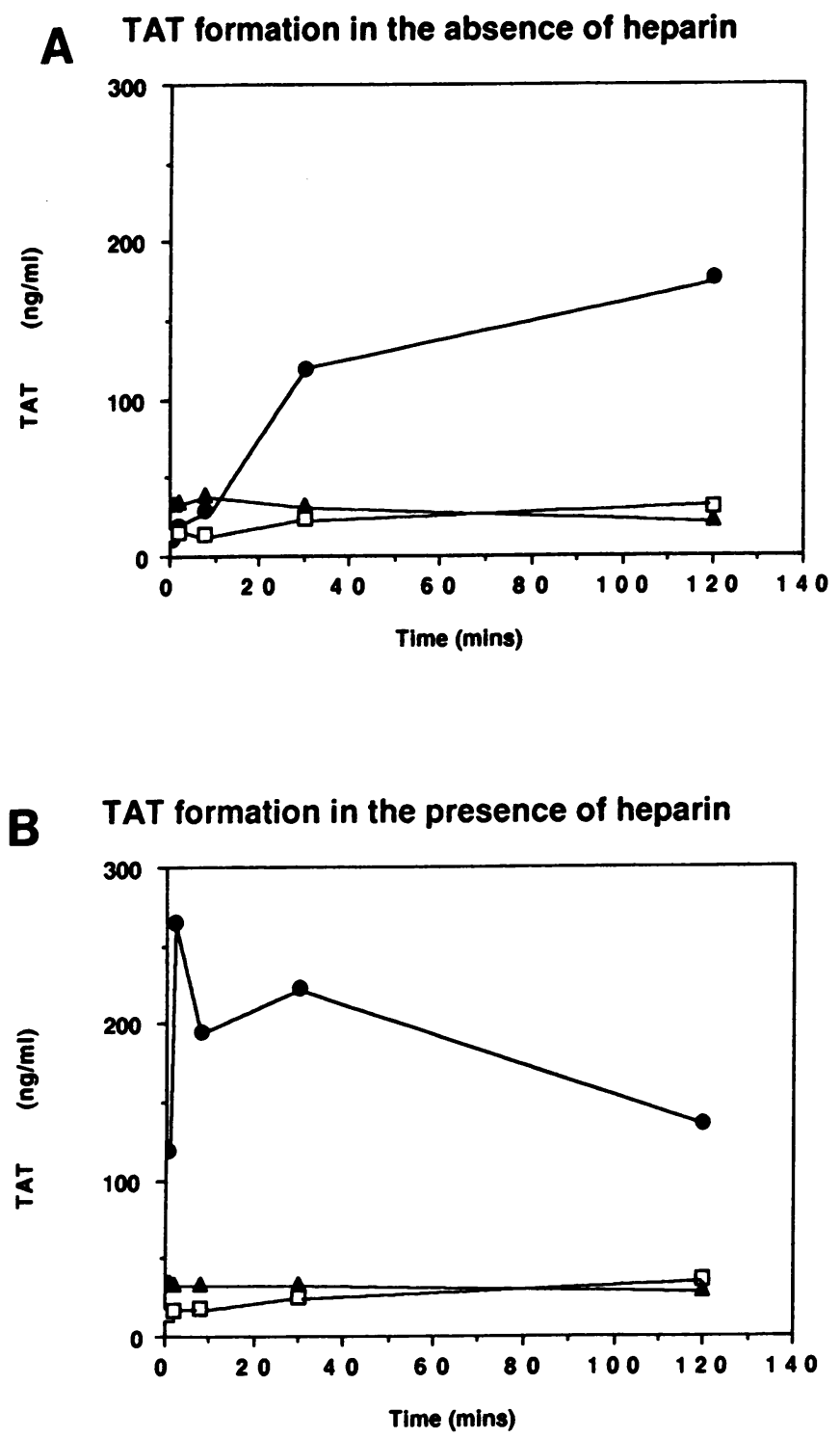

Figure 3. Thrombin-antithrombin complex (TAT) formation. Experiments were performed with normal plasma $(\bullet)$, and the fractions containing antithrombin Rosny ( $\square$ ) and Torino ( $\triangle$ ) that did not bind to heparin-Sepharose in $0.4 \mathrm{M} \mathrm{NaCl}$ (see Fig. 2). Experiments were performed in the absence $(A)$ and presence $(B)$ of heparin. Thrombin, $27 \mathrm{nM}$, was added to each sample that was normalized to a concentration of $5.38 \mathrm{nM}$ and was contained in $50 \mathrm{mM}$ Tris- $\mathrm{HCl}, 150 \mathrm{mM}$ $\mathrm{NaCl}, \mathrm{pH}$ 7.8. TAT formation was determined with an immunoassay (see Methods).

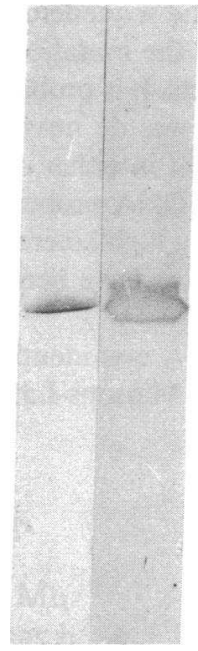

AT Hep-Seph

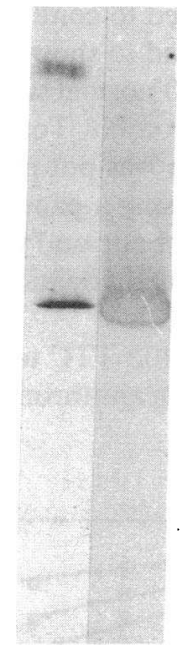

AT Antibody

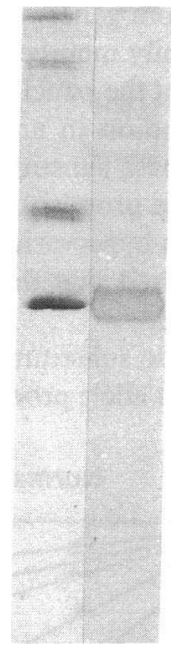

AT Rosny

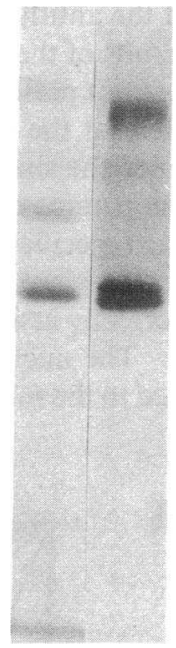

AT Torino
Figure 4. SDS PAGE of purified antithrombins. For each sample, a pair of gels is illustrated, the first stained with Coomassie blue and the second an immunoblot carried out on the sample in a parallel experiment. AT Hep-Seph, normal antithrombin isolated by heparin-Sepharose chromatography; AT Antibody, normal antithrombin isolated by application of normal plasma to the anti-antithrombin column and elution with $\mathrm{MgCl}_{2}$, as indicated in Methods; $A T$ Rosny, antithrombin Rosny purified using heparin-Sepharose chromatography followed by the anti-antithrombin chromatography; $A T$ Torino, antithrombin Torino purified by heparin-Sepharose chromatography followed by anti-antithrombin chromatography.

contaminated by several high molecular weight proteins, visualized after SDS PAGE, Fig. 4. On immunoblotting the only band of antithrombin Rosny had the same mobility as normal antithrombin. In the case of antithrombin Torino, an additional diffuse high molecular weight component reacted with the antibody: its identity could not be ascertained.

After removal of trace contaminating heparin from these antithrombin variant preparations, kinetic experiments were performed to investigate their abilities to inactivate thrombin. A normal antithrombin preparation isolated from normal plasma by chromatography on the immobilized anti-antithrombin column served as a control. As can be seen in Fig. 5, while the normal antithrombin was effective in inhibiting thrombin, only minimal inhibitory effects were observed with the variant protein preparations.

Sequence analysis of the antithrombin genes for families in this series revealed a variety of single base substitutions in the region of exon 6 corresponding to residues 402-407, Fig. 6 . Propositi from three kindreds had different substitutions in the codon for residue 402. The antithrombin Rosny allele contained a single base substitution within codon 402 TTC to TGC, altering the normal Phe to Cys. Allele-specific priming of the PCR confirmed the presence of the mutation in the propositus; the single base substitution was not present in 50 normal individuals.

The antithrombin Torino allele had the mutation 402 TTC to TCC, altering Phe to Ser. Sequence analysis of exon 6 in both parents and the sister of the propositus, each of whom had normal plasma antithrombin assay results, showed only the wild-type sequence. The nucleotide substitution identified created a StyI cutting site; restriction analysis of amplified exon 6 
of the antithrombin gene was used to confirm the sequencing results of the family members, and to show that the mutation was not present in the panel of 50 normal subjects. It is probable that the mutation in antithrombin Torino was de novo, since the single base substitution was not present in either of the parents of the propositus. Using a panel of DNA probes, each specific for a hypervariable region and with a high heterozygosity, we showed that the genetic relationships have been correctly assigned.

The nucleotide substitution 402 TTC to TTA was identified in the mutant allele producing antithrombin Maisons-Laf-
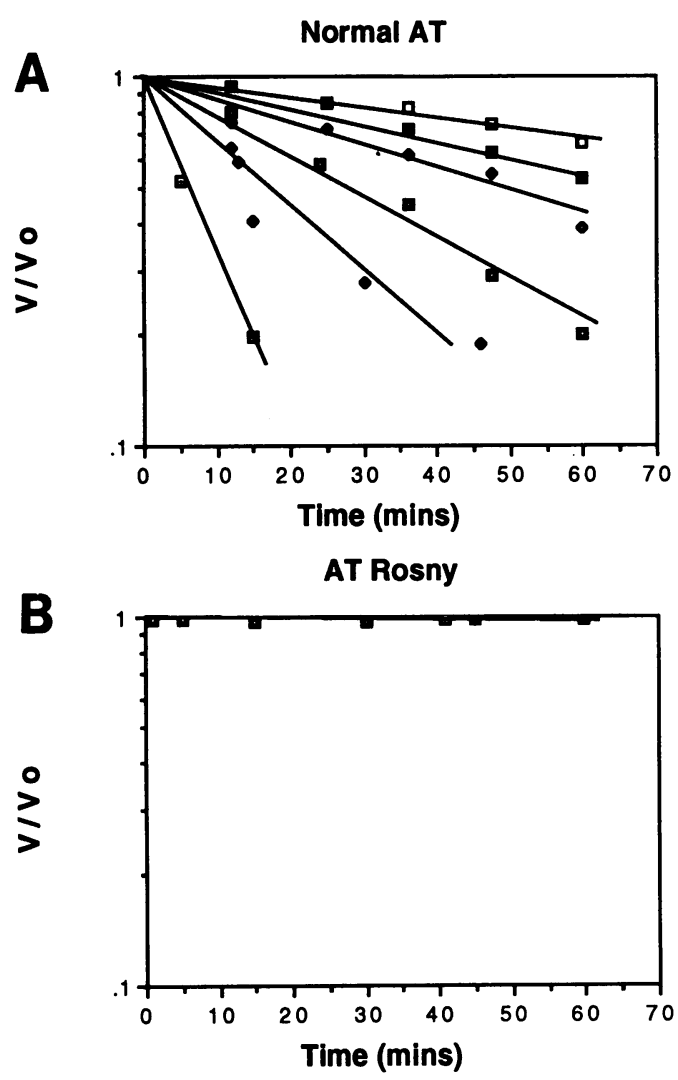

$\mu \mathrm{M}$
$-\quad 0.688$
$-\quad 0.344$
0.115

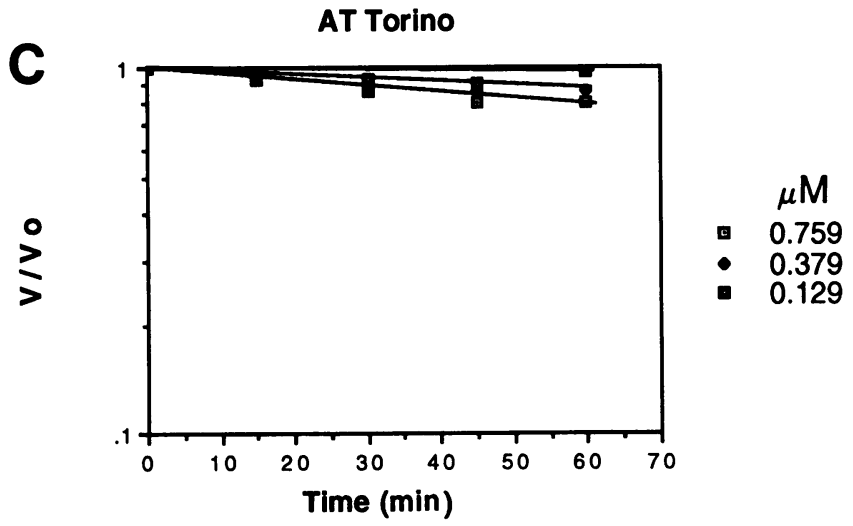

Figure 5. Inactivation of thrombin by purified antithrombins. The graphs show results of the study of normal antithrombin $(A)$, antithrombin Rosny $(B)$, and antithrombin Torino $(C)$. The purified antithrombins at the antigen concentrations indicated, were incubated with $20 \mathrm{nM}$ thrombin in $0.15 \mathrm{M} \mathrm{NaCl}, 0.05 \mathrm{M}$ Tris- $\mathrm{HCl}, \mathrm{pH}$ 7.4 , containing polyethylene glycol 6000 . At different times the reactions were subsampled into the chromogenic substrate S 2238 . Relative velocity of the reactions are plotted against time.
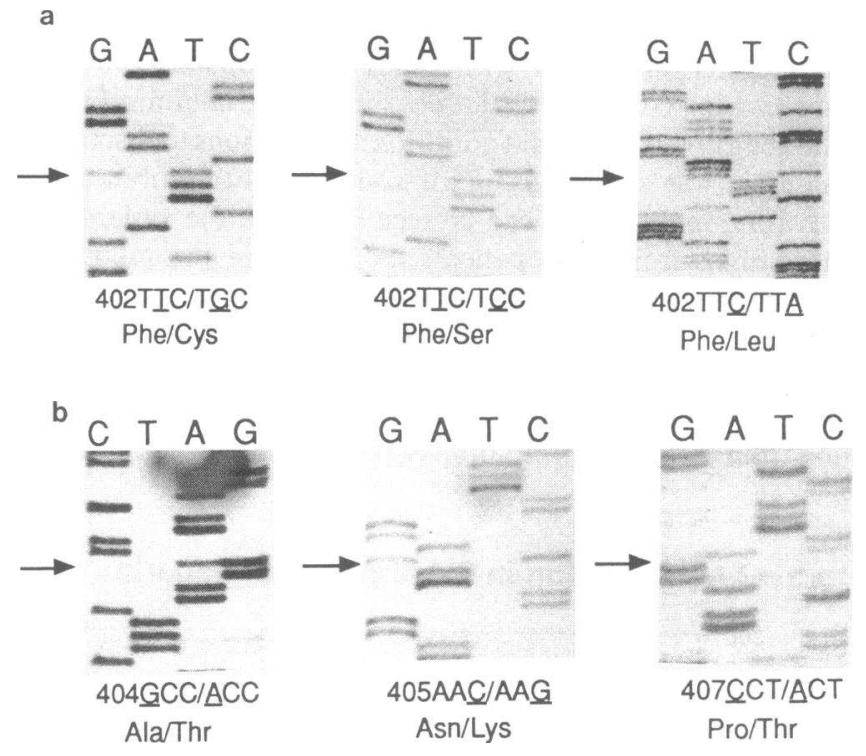

Figure 6. Nucleotide sequencing of antithrombin alleles. DNA amplified by the polymerase chain reaction was purified and directly sequenced (see Methods). The mutations identified within exon 6 in six of the propositi are indicated: $(a)$ left to right, antithrombins Rosny, Torino, Maisons-Laffitte; $(b)$ left to right, antithrombins Paris 3, La Rochelle, Budapest 5 . The sequencing gel demonstrating the mutation causing antithrombin Oslo is not shown as it is essentially identical to that of Paris 3.

fitte, resulting in 402 Phe to Leu. This latter mutation creates a DraI cutting site; DraI restriction analysis was used to confirm the presence of the mutation in one antithrombin allele of the propositus and the one son who had reduced antithrombin assay results, Table I. The mutation was absent in the other kindred members and in 50 normal individuals.
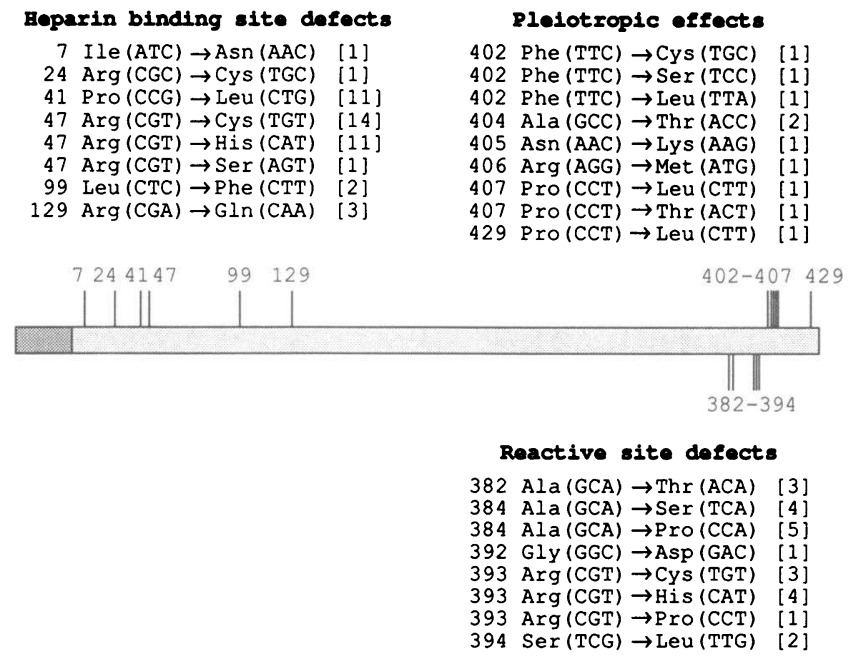

Figure 7. Summary of mutations resulting in the production of naturally occurring variant forms of antithrombin. Many of these mutations are contained in the compilation database (7), which also gives an account of their known frequency of recurrence (shown here in parentheses). This database also lists additional mutations that have not yet been reported fully. Note that the 429 Pro to Leu substitution is grouped with cases having pleiotropic effects. Proline-429 is adjacent to the 402-407 region of the tertiary structure (see Fig. 9) and also has pleiotropic effects upon the function of antithrombin (22). 


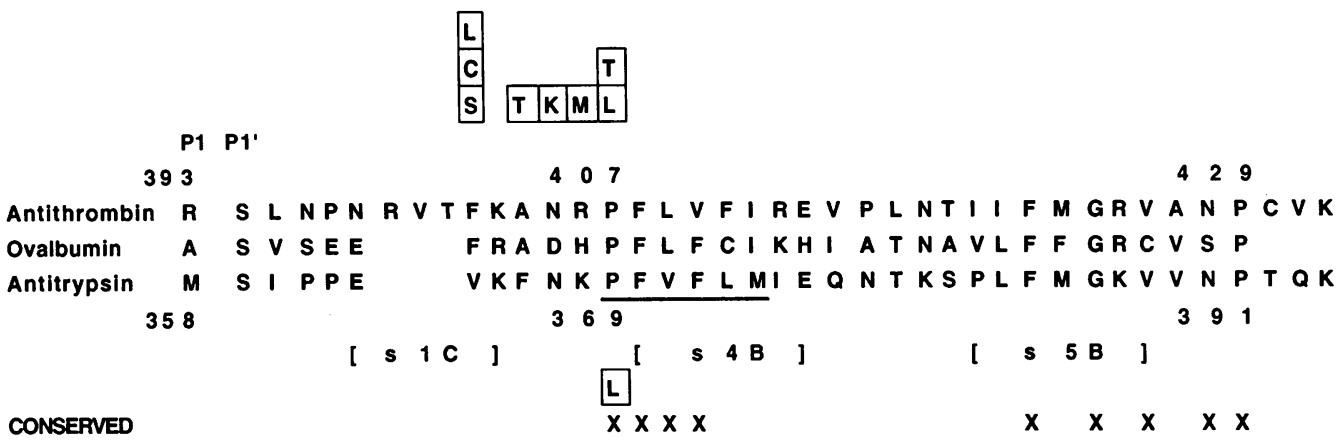
amino acid residues 404, 405, and 407. Antithrombins Paris 3 and Oslo had mutations in codon 404 GCC to ACC, Ala to Thr. The antithrombin Oslo gene segregated with the $\mathrm{S}$ allele of the 5'-end length polymorphism, the $(+)$ allele for the exon 4 PstI site polymorphism and the $(+)$ allele for the intron 5 Ddel site polymorphism. The mutant Paris 3 gene differed at the 5 '-end polymorphic site, being linked to the $F$ allele. This analysis shows that the Oslo and Paris 3 mutations, although having the same nucleotide substitution, are linked with different haplotypes, which supports an independent origin of the mutations.

Antithrombin La Rochelle had an AAC to AAG mutation resulting in a substitution 405 Asn to Lys, and antithrombin Budapest 5 had a CCT to $\mathrm{ACT}$ mutation resulting in a substitution 407 Pro to Thr. This latter nucleotide substitution removes a cleavage site for StuI; restriction analysis of amplified exon 6 DNA with StuI confirmed the presence of a single copy of the mutant allele in the propositus and its absence in the normal subject pool.

Sequencing of all seven exons and the intron-exon boundaries in the antithrombin gene identified no other mutations in the seven propositi, except the propositus with antithrombin La Rochelle was also found to carry the mutation -3 GTG to GAG, Val to Glu. This mutation has been previously described in several kindreds $(7,32)$ and appears not to be responsible for antithrombin deficiency.

\section{Discussion}

The affected seven propositi (and their families) investigated in this study presented in a manner that is typical for molecular abnormalities of coagulation inhibitors causing thrombophilia (33), i.e., the propositi have early onset thromboembolic disease and/or there is an association (not always exact) between phenotype (reduced functional antithrombin plasma assay results) and thrombosis within the families. We have shown the presence of seven variant antithrombins that are functionally impaired in the plasmas of these families and have identified their molecular basis as single amino acid substitutions within the primary sequence $402-407$. The absence of other significant sequence variations within the mutant antithrombin antithrombin and $\alpha_{1}$-antitrypsin. Limits of the $\beta$-strands are indicated, based on the $\mathrm{x}$ ray structure of native ovalbumin (65).
Figure 8. Amino acid alignment of the 402-407 region and flanking sequences. The sequences of human antithrombin, chicken ovalbumin, and human $\alpha_{1}$-antitrypsin "activation peptides" are shown. X indicates residues that are invariant or highly conserved in the serpin gene family alignment (1). Antithrombin and $\alpha_{1}$-antitrypsin amino acid substitutions identified in this report and elsewhere $(31,64,69)$ are

boxed above and below their normal sequences, respectively. Highly conserved elements proposed to be involved in clearance (serpin-enzyme complex receptor ligand [67]) and secretion/folding (proline-369 [69]) are underlined in the $\alpha_{1}$-antitrypsin sequence. Numbering is given for

genes and failure to detect such substitutions in 100 genes from normal healthy individuals, is consistent with the identified mutations being responsible for variant protein production. A notable feature of these mutations is their pleiotropic or multiple effects upon the variant proteins. In this study of the variants we have demonstrated that mutations within or adjacent to antithrombin strand $1 \mathrm{C}$ can impair both the function of the reactive site and heparin binding, as well as causing a reduction in the plasma level of the protein (in all but one case).

The present findings must be considered in the context of previous studies of antithrombin variants. A number of amino acid substitutions in or around the reactive site of antithrombin have been shown to alter its inhibitor function (the fully reported cases are illustrated in Fig. 7). Substitution of $P 1$ residue 393 Arg by Cys, His, and Pro, and P2 residue 392 Gly by Asp, all completely block the inhibitor-proteinase reaction (20, 34-39). Substitution of $P 1^{\prime}$ residue 394 Ser by Leu $(40,41)$ drastically impairs the function of the reactive site when thrombin is the target proteinase, but has less effect upon inhibitory function against Factor $\mathrm{Xa}(42)$. Substitution of $\mathrm{P} 10$ and P12 residues, 384 Ala and 382 Ala, respectively $(38,43,44)$, causes the inhibitory reaction to be transformed into a substrate reaction in which the reactive bond is completely cleaved by the proteinase $(23,45,46)$. Substrate reactions have also been demonstrated for other serpins that have amino acid substitutions or insertions in the P12-P10 region $(47,48)$.

Heparin binding to antithrombin is demonstrably altered by some amino acid substitutions. An antithrombin heparin binding site has been proposed on the basis of genetic data ( 18 , 49-58), together with information from chemical modification experiments (59-61) and the properties of the glycosylation isoform, antithrombin- $\beta(62,63)$. It consists of a surface of high positive charge density around helix $\mathrm{D}$ and the $\mathrm{NH}_{2}$-terminal sequence of antithrombin which is not present on other serpins. Some of the variant antithrombins with altered heparin binding properties have amino acid substitutions that directly affect basic amino acids (e.g., $24 \mathrm{Arg}, 47 \mathrm{Arg}, 129 \mathrm{Arg}$ ), while others have those that are thought to alter the conformation of the binding domain (e.g., 41 Pro, 99 Leu).

The variant forms of antithrombin considered above have been described as having "simple" phenotypes, characterized by defective thrombin interactions in the presence of normal 


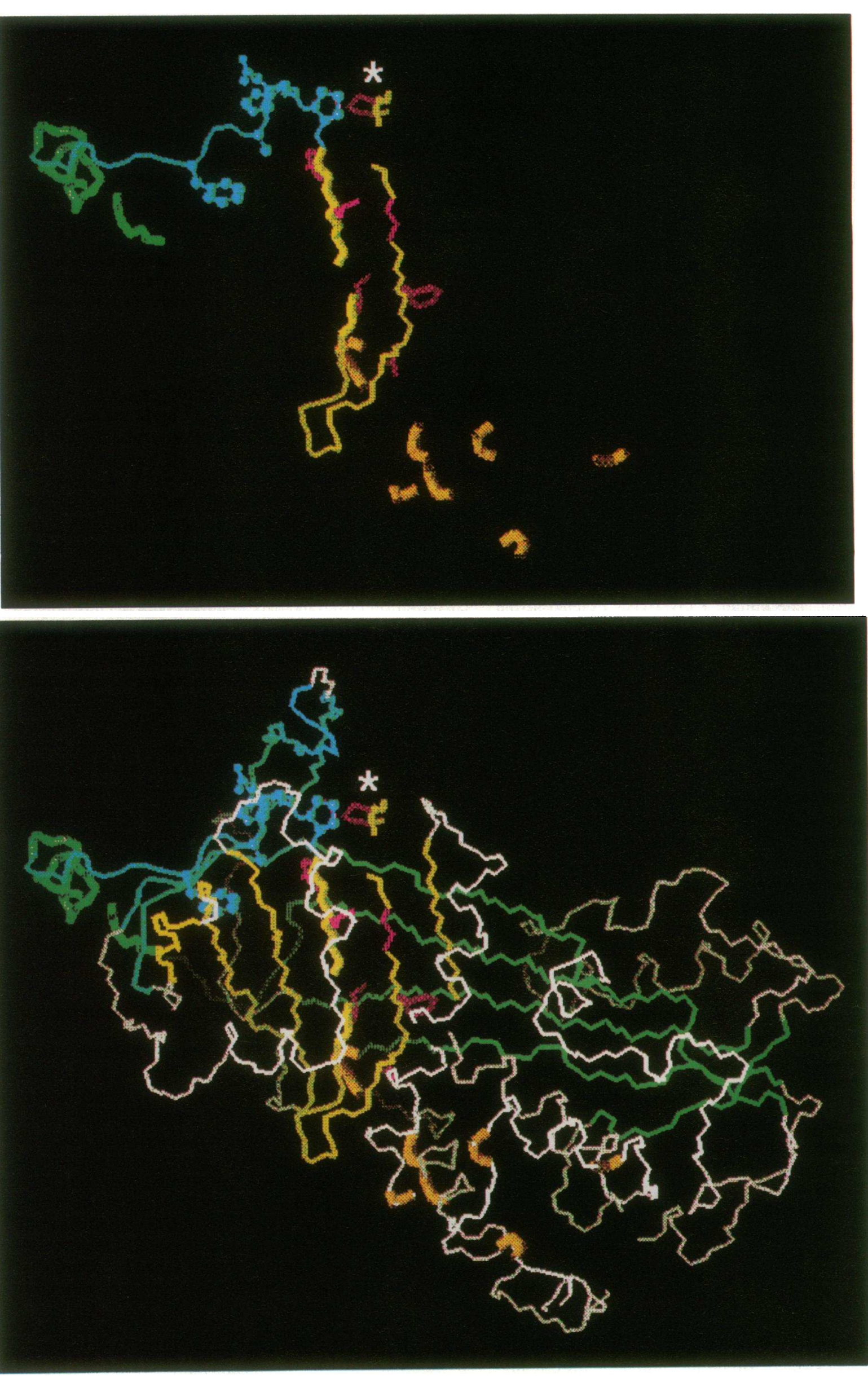


heparin binding, or normal thrombin inhibition in the presence of defective heparin binding. Furthermore, the circulating concentrations of the proteins encoded by the normal and variant alleles in the heterozygous patients are usually similar, and the plasma antithrombin antigen concentration is near normal. In contrast, a total of eight different substitution mutants leading to antithrombin deficiency have now been identified in five positions of the 402-407 region (this report; [ 31,64 ]), see Fig. 7, and these exhibit pleiotropic defects. Fig. 8 shows a sequence alignment for $\mathrm{COOH}$-terminal "activation peptides" of antithrombin, $\alpha_{1}$-antitrysin, and ovalbumin. In the primary structure of antithrombin, the 402-407 region is located between the $\mathrm{P} 1$ residue of the reactive centre and highly conserved regions in strands $4 B$ and $5 B$ of the "activation peptide." The crystal structure of intact ovalbumin (65) can serve as a working prototype for the three dimensional structures of native (reactive loop intact) serpins, Fig. 9. Antithrombin residues 402-407 map to strand $1 \mathrm{C}$ and the polypeptide leading into strand $4 \mathrm{~B}$. The positions of the reactive site, heparin-binding site, and conserved elements of the "activation peptide" are marked in Fig. 9, and the functional consequences of the 402407 mutations will be considered in terms of this model.

In vitro studies of purified antithrombins Rosny and Torino (Fig. 5) and antithrombin Utah in plasma (31) revealed defective interactions with thrombin. Based on their presence in patients with clinical thrombosis, it is likely that the other 402-407 region variants also have abnormal interactions with thrombin. The P1 residue of antithrombin, $393 \mathrm{Arg}$, is the primary determinant of thrombin target specificity and interacts with the enzyme active site. However, because antithrombin inhibits thrombin more efficiently than several other serpins that also have arginine P1 residues ( $\alpha_{2}$-antiplasmin, PAI1, PAI-2, $\mathrm{Cl}$ inhibitor, and protein $\mathrm{C}$ inhibitor), it can be inferred that an extended inhibitor-enzyme contact surface surrounding the $P 1$ residue participates in the recognition and inhibition of target enzymes by serpins. Inspection of Fig. 9 shows that the 402-407 region is in close proximity to the reactive loop containing the $\mathrm{P} 1$ residue, and may constitute part of the extended contact surface or be very close to it. Thus, based on their location near the $P 1$ residue, mutations in the 402-407 region may block antithrombin-protease interactions directly or indirectly.

Heparin binding abnormalities have been demonstrated in seven 402-407 region variants by CIE of plasma (Fig. 1). Decreased heparin affinity was confirmed for antithrombins Rosny and Torino by heparin-Sepharose chromatography (Fig. 2), but not for antithrombin Utah (31). Elements of the heparin-binding site are found on the lower face of the mole- cule shown in Fig. 9. The heparin-binding site is distinct from the reactive site and the region containing 402-407 (upper part of the molecule shown), and spatially removed from them. Therefore, barring overall denaturation of the variants, the presence of heparin binding abnormalities in these mutants suggests that the reactive site end of antithrombin (containing the 402-407 region) is linked conformationally to the heparinbinding site at the other side of the molecule. The converse of this idea is the basis of conformation-based hypotheses to explain antithrombin heparin cofactor activity $(3,4)$. The 402407 substitutions map to strand $1 \mathrm{C}$ and the polypeptide leading into $\mathrm{s} 4 \mathrm{~B}$, and constitute a significant part of the interface between the $C$ sheet at the reactive site pole of the inhibitor, and the internal B sheet which connects at its other end to alpha helices, forming the heparin-binding site of antithrombin (Fig. $9 \mathrm{~B}$ ). Thus, mutations in the $402-407$ region may relay structural changes to the distal heparin binding site by perturbing the B sheet and the core of the molecule. In the extreme, it is possible that inducing perturbations in the core may disrupt protein folding and lead to a phenomenon of general protein denaturation, which would also be associated with a phenotype of defective target enzyme and cofactor interactions and decreased plasma levels.

Decreased circulating concentrations of several 402-407 region variants have been detected by CIE (Fig. 1) and Western blotting (31) and it had been suggested that integrity of this region is necessary for obtaining normal circulating serpin levels $(66,67)$. Quantitative deficiencies of antithrombin 402407 variants could be caused by decreased synthesis, increased intracellular degradation, impaired secretion, and/or increased turnover. Two highly conserved elements of the activation peptide map near to 402-407 in the tertiary structure and are thought to play important roles in regulating serpin intracellular degradation and turnover. Brodbeck and Brown noted that $\mathrm{COOH}$-terminal frameshift mutations caused secretory defects in naturally occurring $\alpha_{1}$-antitrypsin mutants and used an in vitro mutagenesis approach to show that truncations before invariant proline-391 (marked with an asterisk in Fig. 9) are associated with intracellular degradation and prevent movement of the protein from the endoplasmatic reticulum to the Golgi apparatus (68). Thus, intracellular degradation and decreased secretion may occur for some of the antithrombin 402407 variants as a consequence of structural perturbations extending from the immediate vicinity of the substitutions to the region of the invariant proline (residue 391 in $\alpha_{1}$-antitrypsin ). Alternatively, accelerated turnover may be the mechanism responsible for quantitative deficiencies of some 402-407 variants in which structural abnormalities caused by the substitu-

Figure 9. Ovalbumin model (69) for intact serpin structure showing locations of antithrombin 402-407 substitution mutations relative to the reactive loop, the heparin-binding site, and the highly conserved regions of the activation peptide. Several discontinuities present in the polypeptide backbone are caused by low electron density in these portions of the crystal structure. Structural elements of interest are shown in the top view. The reactive loop is on the left and drawn in green. Strand $1 \mathrm{C}$ and the polypeptide leading into strand 4B are blue. Side chains of the ovalbumin residues corresponding to substituted residues of antithrombin 402 and 403-407 variants are shown in ball and stick rendering. Side chains of invariant and highly conserved residues in strands $4 B$ and 5B (yellow) of the activation peptide are red. The main chain of residue corresponding to invariant glycine 386 ( $\alpha_{1}$-antitrypsin) is also red. The proposed ligand for the serpin-enzyme complex receptor (67) is located in strand $4 \mathrm{~B}$ and is rendered in cylindrical format. Ovalbumin residues corresponding to antithrombin residues assigned to the heparin-binding site by chemical modification, genetic variant, and glycosylation isoform evidence are orange. The asterisk marks the invariant proline of ovalbumin that corresponds to proline-429 of antithrombin (altered in antithrombin Budapest (22)), and to proline-391 of $\alpha_{1}$-antitrypsin (required for normal secretion in vitro [69]). The bottom view shows structural elements introduced in the top view in the context of the entire molecule. Beta-sheets A, B, and C are drawn in green, yellow, and blue, respectively. 
tions lead to exposure of a highly conserved neoepitope (Fig. 9 ), proposed to serve as a ligand for hepatic serpin-enzyme complex receptors (67). It is notable that the quantitative deficiency phenotype of $\alpha_{1}$-antitrypsin Heerlen (69), which carries a leucine for proline substitution at the residue (369) corresponding to antithrombin 407 (see Fig. 8), suggests that this region of serpins is generally involved in determining circulating protein level.

In summary, the pleiotropic effects of antithrombin 402407 substitution mutants can be rationalized in terms of a three-dimensional model derived from the crystal structure of native ovalbumin. The strand $1 \mathrm{C}$ region containing the $402-$ 407 mutations is contiguous with the reactive site and two highly conserved elements of the activation peptide that may play important roles in regulating serpin intracellular degradation and plasma clearance; this may explain defective interactions of s1C mutants with thrombin, and their low circulating levels. In contrast, $\mathrm{s} 1 \mathrm{C}$ is distal to the positively charged surface which forms the heparin binding site of heparin; altered heparin-binding properties of the $\mathrm{SIC}$ variants may therefore reflect conformational linkage between the reactive site and heparinbinding regions of the molecule. Alternatively, integrity of the 402-407 region may be required for antithrombin to fold correctly, and the pleiotropic effects of s1C substitutions may represent the consequences of general protein denaturation. Finally, it is interesting that the antithrombin Budapest variant (22) exhibits pleiotropic reactive site and heparin-binding site defects, and carries a substitution (P429L) that maps near the 402-407 region in the tertiary structure (Fig. 9), but not the primary structure.

\section{Acknowledgments}

Antithrombin Utah plasma was generously provided by Dr. John Ward. We thank J. Silberman, W. Wikoff, and P. van Dreden for excellent technical assistance.

This work was supported by grants from the Wellcome Trust and British Heart Foundation, U.S. Public Health Service HL-30712 (to S. Bock) and American Heart Association Established Investigatorship 88-0261 (to S. Bock).

\section{References}

1. Huber, R., and R. W. Carrell. 1989. Implications of the three dimensional structure of $\alpha_{1}$ antitrypsin for structure and function of serpins. Biochemistry. 28:8951-8966.

2. Abildgaard, U. 1969. Binding of thrombin to antithrombin III. Scand. J. Clin. Lab. Invest. 24:23-27.

3. Rosenberg, R. D., and P. S. Damus. 1973. The purification and mechanism of action of human antithrombin-heparin cofactor. J. Biol. Chem. 248:64906505 .

4. Bjork, I., S. T. Olson, and J. D. Shore. 1989. Molecular mechanisms of the accelerating effect of heparin on the reactions between antithrombin and the clotting proteinases. In Heparin: Chemical and Biological Properties, Clinical Applications. D. A. Lane and U. Lindahl, editors. Edward Arnold, London. 229-255.

5. Finazzi, G., R. Caccia, and T. Barbui. 1987. Different prevalence of thromboembolism in the subtypes of congenital antithrombin III deficiency: review of 404 cases. Thromb. Haemostasis. 58:1094.

6. Lane, D. A., and R. Caso. 1989. Antithrombin: structure, genomic organization, function and inherited deficiency. Bailliere Clin. Haematol. 2:961-998.

7. Lane, D. A., H. Ireland, R. J. Olds, S. L. Thein, D. J. Perry, and M. Aiach. 1991. Antithrombin III: a database of mutations. Thromb. Haemostasis. 66:657661.

8. Sas, G., D. Banhegyi, G. Blasko, and G. Domjam. 1980. Heterogeneity of the "classical" antithrombin III deficiency. Thromb. Haemostasis. 43:133-136.

9. Sas, G. 1984. Hereditary antithrombin III deficiency: biochemical aspects. Haematologia. 7:81-86.
10. Sas, G., and A. Pal. 1990. Severe familial thrombophilia caused by the combination of protein $\mathrm{C}$ deficiency and minor qualitative disturbance of antithrombin III production. Thromb. Haemorrh. Disorders. 1:29-32.

11. Egeberg, O. 1965. Inherited antithrombin III deficiency causing thrombophilia. Thromb. Diath. Haemorrh. 13:516-530.

12. Hultin, M. B., J. McKay, and U. Abildgaard. 1988. Antithrombin Oslo: type Ib classification of the first reported antithrombin-deficient family with a review of the hereditary antithrombin variants. Thromb. Haemostasis. 59:468473.

13. Abildgaard, U., M. K. Fagerhold, and O. Egeberg. 1970. Scand. J. Clin. Lab. Invest. 26:349-354.

14. Hensen, E., and E. A. Loeliger. 1963. Antithrombin III. Its metabolism and its function in blood coagulation. Thromb. Diath. Haemorrh. 9:1-84.

15. Sas, G., D. S. Pepper, and J. D. Cash. 1975. Plasma and serum antithrombin III: differentiation by crossed immunoelectrophoresis. Thromb. Res. 6:8794.

16. Lane, D. A., A. Flynn, H. Ireland, H. Erdjument, D. Samson, D. Howarth, and E. Thompson. 1987. Antithrombin III Northwick Park: demonstration of a high MW complex with increased affinity for heparin. Br. J. Haematol. 65:451456.

17. Lane, D. A., G. D. O. Lowe, A. Flynn, E. Thompson, H. Ireland, and H. Erdjument. 1987. Antithrombin III Glasgow: a variant with increased heparin affinity and reduced ability to inactivate thrombin, associated with familial thrombosis. Br. J. Haematol. 66:523-527.

18. Gandrille, S., M. Aiach, D. A. Lane, D. Vidaud, P. Mohlo-Sabatier, R. Caso, P. de Moerloose, J. N. Fiessinger, and E. Clauser. 1990. Important role of Arg 129 in heparin binding site of antithrombin III: identification of novel mutation Arg 129 to Gln. J. Biol. Chem. 265:18997-19001.

19. Molloy, C., M. C. Owen, and R. C. Boswell. 1989. Immunoadsorbent purification of antithrombin: active and inactive variants. Thromb. Res. 55:657660 .

20. Erdjument, H., D. A. Lane, M. Panico, V. diMarzo, and H. R. Morris. 1988. Single amino acid substitutions in the reactive site of antithrombin leading to thrombosis. Congenital substitution of arginine 393 to cysteine in antithrombin Northwick Park and to histidine in antithrombin Glasgow. J. Biol. Chem. 263:5589-5593.

21. Erdjument, H., D. A. Lane, H. Ireland, M. Panico, V. DiMarzo, I. Blench, and H. R. Morris. 1987. Formation of a covalent disulfide-linked antithrombin complex by an antithrombin variant, antithrombin Northwick Park. J. Biol. Chem. 262:13381-13384.

22. Olds, R. J., D. A. Lane, R. Caso, M. Panico, H. R. Morris, G. Sas, J. Dawes, and S. L. Thein. 1992. Antithrombin III Budapest: a single amino acid substitution (429 Pro to Leu) in a region highly conserved in the serpin super family. Blood. 79:1206-1212.

23. Caso, R., D. A. Lane, E. A. Thompson, R. J. Olds, S. L. Thein, M. Panico, I. Blench, H. Morris, J. M. Freyssinet, M. Aiach, et al. 1991. Antithrombin Vicenza, Ala 384 to Pro (GCA to CCA) mutation transforming the inhibitor into a substrate. Br. J. Haematol. 77:87-92.

24. Olds, R. J., D. A. Lane, G. Finazzi, T. Barbui, and S. L. Thein. 1990. A frameshift mutation leading to type 1 antithrombin deficiency and thrombosis. Blood. 76:2182-2186.

25. Olds, R. J., D. A. Lane, H. Ireland, G. Leone, V. De Stefano, M. L. Wiesel, J. P. Cazenave, and S. L. Thein. 1991. Novel point mutations leading to type I antithrombin deficiency and thrombosis. Br. J. Haematol. 78:408-413.

26. Thein, S. L., and J. Hinton. 1991. A simple and rapid method of direct sequencing using Dynabeads. Br. J. Haematol. 79:113-115.

27. Bock, S. C., and D. J. Levitan. 1983. Characterisation of an unusual length polymorphism 5' to the antithrombin III gene. Nucleic Acids Res. 11:8569-8582.

28. Prochownik, E. V., S. Antonarakis, K. A. Bauer, R. D. Rosenberg, E. R. Fearon, and S. H. Orkin. 1983. Molecular heterogeneity of inherited antithrombin III deficiency. $N$. Engl. J. Med. 308:1549-1552.

29. Daly, M. E., and D. J. Perry. 1990. Dde I polymorphism in intron 5 in the antithrombin III gene. Nucleic Acids Res. 18:5583.

30. Wong, Z., V. Wilson, I. Patel, S. Povey, and A. J. Jeffries. 1987. Characterisation of a panel of highly variable mini satellites cloned from human DNA. Ann. Hum. Genet. 71:269-288.

31. Bock, S. C., J. A. Marrinan, and E. Radziejewska. 1988. Antithrombin III Utah: proline 407 to leucine mutation in a highly conserved region near the inhibitor reactive site. Biochemistry. 27:6171-6178.

32. Daly, M., D. Bruce, D. J. Perry, J. Price, P. L. Harper, A. O'Meara, and R. W. Carrell. 1990. Antithrombin Dublin (-3 Val to Glu ): an N-terminal variant which has an aberrant signal peptide cleavage site. FEBS (Fed. Eur. Biochem. Soc.) Lett. 273:87-90.

33. Haemostasis and Thrombosis Task Force. 1990. The British Society for Haematology: guidelines on the investigation and management of thrombophilia. J. Clin. Pathol. (Lond.). 43:703-710.

34. Erdjument, H., D. A. Lane, H. Ireland, V. DiMarzo, M. Panico, H. R. Morris, A. Tripodi, and P. M. Mannucci. 1988. Antithrombin Milano, single 
amino acid substitution at the reactive site, Arg 393 to Cys. Thromb. Haemostasis. 60:471-475.

35. Erdjument, H., D. A. Lane, M. Panico, V. DiMarzo, H. R. Morris, K. Bauer, and R. D. Rosenberg. 1989. Antithrombin Chicago, amino acid substitution of arginine 393 to histidine. Thromb. Res. 54:613-619.

36. Lane, D. A., H. Erdjument, E. Thompson, M. Panico, V. DiMarzo, H. R. Morris, G. Leone, V. De Stefano, and S. L. Thein. 1989. A novel amino acid substitution in the reactive site of a congenital variant antithrombin. Antithrombin Pescara, Arg 393 to Pro, caused by CGT to CCT mutation. J. Biol. Chem. 264:10200-10204.

37. Lane, D. A., H. Erdjument, A. Flynn, V. DiMarzo, M. Panico, H. Morris, M. Greaves, G. Dolan, and F. E. Preston. 1989. Antithrombin Sheffield: amino acid substitution at the reactive site (Arg 393 to His) causing thrombosis. Br. J. Haematol. 71:91-96.

38. Mohlo-Sabatier, P., M. Aiach, I. Gaillard, J. N. Fiessinger, A. M. Fischer, G. Chadeuf, and E. Clauser. 1989. Molecular characterization of antithrombin III (AT III) variants using polymerase chain reaction. Identification of the ATIII Charleville as an Ala384 Pro mutation. J. Clin. Invest. 84:1236-1241.

39. Blajchman, M. A., F. Fernandez-Rachubinsky, W. P. Sheffield, R. C. Austin, and S. Schulman. 1992. Antithrombin III Stockholm: a codon 392 (Gly to Asp) mutation with normal heparin binding and impaired serine protease reactivity. Blood. 79:1428-1434.

40. Olds, R. J., D. Lane, R. Caso, A. Tripodi, P. M. Mannucci, and S. L. Thein. 1989. Antithrombin III Milano 2: a single base substitution in the thrombin binding domain detected with PCR and direct genomic sequencing. Nucleic Acids Res. 17:10511.

41. Stephens, A. W., B. S. Thalley, and C. H. W. Hirs. 1987. Antithrombin Denver, a reactive site variant. J. Biol. Chem. 262:1044-1048.

42. Olson, S. T., R. Sheffer, A. W. Stephens, and C. H. W. Hirs. 1991. Molecular basis of the reduced activity of antithrombin-Denver with thrombin and factor $\mathrm{Xa}$. Role of the $\mathrm{P}^{\prime} 1$ residue. Thromb. Haemostasis. 65:670.

43. Devraj-Kizuk, R., D. H. K. Chui, E. V. Prochownik, C. J. Carter, F. A. Ofosu, and M. A. Blajchman. 1988. Antithrombin III Hamilton: a gene with a point mutation (guanine to adenine) in codon 382 causing impaired serine protease reactivity. Blood. 72:1518-1523.

44. Perry, D. J., M. Daly, P. L. Harper, R. C. Tait, J. Price, I. D. Walker, and R. W. Carrell. 1991. Antithrombin Cambridge II, 384 Ala to Ser. Further evidence of the role of the reactive centre loop in the inhibitory function of the serpin. FEBS (Fed. Eur. Biochem. Soc.) Lett. 285:248-250.

45. Ireland, H., D. A. Lane, E. Thompson, I. D. Walker, I. Blench, H. R. Morris, J. M. Freyssinet, L. Grunebaun, R. Olds, and S. L. Thein. 1991. Antithrombin Glasgow II: alanine to threonine mutation in the serpin P12 position, resulting in a substrate reaction with thrombin. Br. J. Haematol. 79:70-74.

46. Austin, R. C., R. A. Rachubinski, F. A. Ofosu, and M. A. Blajchman 1991. Antithrombin-III-Hamilton, Ala 382 to Thr: an antithrombin -III variant that acts as a substrate but not an inhibitor of $\alpha$-thrombin and Factor Xa. Blood. 77:2185-2189.

47. Skriver, K., W. R. Wikoff, P. A. Patston, F. Tausk, M. Schapira, A. P Kaplan, and S. C. Bock. 1991. Substrate properties of Cl inhibitor Ma (A434E) Genetic and structural evidence suggesting that the 'P12-region' contains critical determinants of serpin inhibitor/substrate status. J. Biol. Chem. 266:9216-9221.

48. Rijken, D. C., E. Groeneveld, C. Kluft, and H. K. Nieuwenhuis. 1988. Alpha2-antiplasmin Enschede is not an inhibitor, but a substrate of plasmin. Biochem. J. 255:609-615.

49. Borg, J. Y., M. C. Owen, C. Soria, J. Soria, J. Caen, and R. W. Carrell. 1988. Arginine 47 is a prime heparin binding site in antithrombin. A new variant Rouen II, 47 Arg to Ser. J. Clin. Invest. 81:1292-1296.

50. Borg, J. Y., S. O. Brennan, R. W. Carrell, P. George, D. J. Perry, and J. Shaw. 1990. Antithrombin Rouen IV 24 Arg to Cys. The amino terminal contribution to heparin binding. FEBS (Fed. Eur. Biochem. Soc.) Lett. 266:163-166. 51. Brunel, F., N. Duchange, A. M. Fischer, G. N. Cohen, and M. M. Zakin.
1987. Antithrombin III Alger: a new case of Arg 47 - Cys mutation. Am. J. Hematol. 25:223-224.

52. Caso, R., D. A. Lane, E. Thompson, D. Zangouras, M. Panico, H. Morris, R. J. Olds, S. L. Thein, and A. Girolami. 1990. Antithrombin Padua I: impaired heparin binding caused by an Arg 47 to His (CGT to CAT) substitution. Thromb. Res. 58:185-190.

53. Chang, J. Y., and T. H. Tran. 1986. Antithrombin Basel. Identification of Pro-Leu substitution in a hereditary abnormal antithrombin with impaired heparin cofactor activity. J. Biol. Chem. 261:1174-1176.

54. Duchange, N., J. F. Chasse, G. N. Cohen, and M. M. Zakin. 1986. Identification of a mutation leading to cysteine replacement in a silent deficiency. Nucleic Acids Res. 14:2408.

55. Koide, T., S. Odani, K. Takahashi, T. Ono, and N. Sakuragawa. 1984 Antithrombin III Toyama: replacement of Arginine 47 by Cysteine in hereditary abnormal antithrombin III that lacks heparin-binding ability. Proc. Natl. Acad. Sci. USA 81:289-293.

56. Olds, R. J., D. A. Lane, M. Boisclair, G. Sas, S. C. Bock, and S. L. Thein. 1992. Antithrombin Budapest 3: an antithrombin variant with reduced heparin affinity resulting from the substitution L99F. FEBS (Fed. Eur. Biochem. Soc.) Lett. 300:241-246.

57. Owen, M. C., J. Y. Borg, C. Soria, J. Soria, J. Caen, and R. W. Carrell. 1987. Heparin binding defect in new antithrombin III variant: Rouen, 47 Arg to His. Blood. 69:1275-1279.

58. Brennan, S. O., J. Y. Borg, P. M. George, C. Soria, J. Soria, J. Caen, and R. W. Carrell. 1988. New carbohydrate site in mutant antithrombin (7Ile-Asn) with decreased heparin affinity. FEBS (Fed. Eur. Biochem. Soc.) Lett. 237:118122.

59. Blackburn, M. N., R. L. Smith, J. Carson, and C. C. Sibley. 1984. The heparin binding site of antithrombin III. Identification of a critical tryptophan in the amino acid sequence. J. Biol. Chem. 259:939-941.

60. Chang, J. Y. 1989. Binding of heparin to antithrombin III activates selective chemical modification at lysine 236 . Lys-107, Lys-125 and Lys- 136 are situated within the heparin binding site of antithrombin III. J. Biol. Chem. 264:3111-3115.

61. Sun, X. J., and J. Y. Chang. 1990. Evidence that arginine-129 and arginine-145 are located within the heparin binding site of human antithrombin III. Biochemistry. 29:8957-8962.

62. Peterson, C. B., and M. N. Blackburn. 1985. Isolation and characterisation of an antithrombin III variant with reduced carbohydrate content and enhanced heparin binding. J. Biol. Chem. 260:610-615.

63. Brennan, S. O., P. M. George, and R. E. Jordan. 1987. Physiological variant of antithrombin lacks carbohydrate side chain at Asn 135. FEBS (Fed. Eur. Biochem. Soc.) Lett. 219:431-436.

64. Nakagawa, M., S. Tanaka, H. Tsuji, O. Takada, and T. Ono. 1991. Congenital antithrombin deficiency (ATIII Kyoto): identification of a point mutation altering arginine-406 to methionine behind the reactive site. Thrombos. Res. 64:101-108.

65. Stein, P. E., A. G. W. Leslie, J. T. Finch, and R. W. Carrell. 1991. Crystal structure of uncleaved ovalbumin at 1.95A resolution. J. Mol. Biol. 221:941959.

66. Bock, S. C. 1991. Antithrombin III genetics, structure and function. In Recombinant Technology in Hemostasis and Thrombosis. L. Hoyer and W. Drohan, editors. Plenum Publishing Corp., New York. 25-46.

67. Joslin, G., R. J. Fallon, J. Bullock, S. P. Adams, and D. H. Perlmutter 1991. The SEC receptor recognizes a pentapeptide neodomain of alphal-antitrypsin-protease complexes. J. Biol. Chem. 266:11282-11288.

68. Brodbeck, R. M., and J. L. Brown. 1992. Secretion of a-1-proteinase inhibitor requires an almost full length molecule. J. Biol. Chem. 267:294-297.

69. Hofker, M. H., T. Nukiwa, H. M. B. vanPaassen, M. Nelen, R. R. Frants, E. C. Klasen, and R. G. Crystal. 1987. A pro to leu substitution in codon 369 in the al-antitrypsin variant PIM-Heerlen. Am. J. Hum. Genet. 41:A220. 